\title{
A crise dos lugares de memória e dos espaços identitários no contexto da modernidade: questões para o ensino de história
}

DANIEL LUCIANO GEVEHR Faculdades Integradas de Taquara, Taquara, RS, Brasil

\section{RESUMO}

Esta pesquisa discute os impactos da modernidade e suas diferentes dimensões culturais para o ensino da história tomando como base a leitura da realidade encontrada nos diferentes contextos da escola de educação básica da contemporaneidade brasileira. Discutimos como as redefinições dos modelos que orientam o ensino da história - antes pautados em memorizações, linearidades e heroicizações - hoje apresentam novos problemas, como a crise da memória, das identidades e da desvalorização (ou esquecimentos) dos lugares de memória (Nora, 1993) produzidos historicamente pelos diferentes grupos sociais, que passam a não mais reconhecer esses espaços como representantes de seu passado. A pesquisa insere-se no campo das discussões sobre os impactos sociais da modernidade líquida (Bauman, 2003) e procura desvendar como as transformações ocorridas na sociedade atual produziram novas formas de (re)pensar o passado.

\section{PALAVRAS-CHAVE}

modernidade; ensino de história; lugares de memória. 


\section{THE CRISIS OF PLACES OF MEMORY AND SPACES OF IDENTITY IN THE MODERN CONTEXT: QUESTIONS FOR THE HISTORY EDUCATION}

\section{ABSTRACT}

The research discusses the impacts of modernity and its different cultural dimensions in the history education, from the reading of reality found in different context of basic education school of Brazilian contemporary. We discuss how the redefinitions of the models that guide the history education - before ruled on memorizing, linearity and heroicizations - today present new problems such as memory's crisis, identity and devaluation (or forgettings) of the places of memory (Nora, 1993) produced by historically different social groups, who spend no more recognize these spaces as representatives of their past. Our research belongs to the field of discussions on the social impacts of liquid modernity (Bauman, 2003) and seeks to reveal how the transformations that occurred in today's society have produced new forms of (re)think about the past.

KEYWORDS

modernity; history education; places of memory.

\section{LA CRISIS DE LUGARES Y ESPACIOS DE IDENTIDAD DE MEMORIA EN LA MODERNIDAD: CUESTIONES PARA LA ENSEÑANZA DE LA HISTORIA}

\section{RESUMEN}

En este artículo se analiza el impacto de la modernidad y sus diferentes dimensiones culturales a la enseñanza de la historia, a partir de la lectura de la realidad que se encuentra en las diferentes áreas del sistema de educación primaria en contemporánea brasileña. Se discute cómo las redefiniciones de los modelos que orientan la enseñanza de la historia -antes gobernaron en la memorización, la linealidad y de una forma heroicaahora tienen nuevos problemas, como la crisis de la memoria, la identidad y la devaluación (u omisiones) de los lugares de la memoria (Nora, 1993) producido históricamente por diferentes grupos sociales, que pasan ahora ya no reconocer estos espacios como representantes de su pasado. Nuestra investigación en el campo de las discusiones sobre los impactos sociales de la modernidad líquida (Bauman, 2003) y trata de descubrir cómo los cambios que se producen en la sociedad actual se han producido nuevas formas de (re)pensar el pasado.

PALABRAS CLAVE

modernidade; la enseñanza de la historia; lugares de la memoria. 


\section{CONSIDERAÇÕES INICIAIS}

As transformações ocorridas em âmbito mundial nas últimas décadas nos colocaram diante de novos questionamentos e de novos desafios perante as questões que envolvem a educação, seus paradigmas, metodologias e preocupações. A escola, que antes muitas vezes se preocupava essencialmente com a transmissão passiva de saberes e conteúdos alocados de tal forma que o aluno tivesse condições de enfrentar provas e exames nos quais precisava "provar" que havia aprendido, atualmente enfrenta outros dilemas. Hoje a pauta da escola mudou e certamente é preciso rever os processos inerentes ao seu espaço, que manifesta uma necessidade latente de mudança e ressignificação de seus sujeitos e processos.

A emergência dos novos modelos - se assim é que podemos chamá-los - fez com que o ensino e por consequência os professores, seus agentes, buscassem estratégias para "dar conta" das novas demandas que a sociedade e a escola impuseram.

Nesse sentido, a escola dos tempos atuais, imersa naquilo que Bauman (2003) chamou de modernidade líquida, tem passado por profundas mudanças paradigmáticas não apenas no que tange à escolha daquilo que se ensina, mas também sobre como e por que se ensina. A liquidez dessa modernidade, inscrita e presente em nossos dias, faz-nos repensar sobre o entendimento que temos a respeito da sociedade e da própria dinâmica presente nos diferentes elementos que ela produz e por meio dos quais ela também é produzida.

Essa desconstrução proposta por Bauman também nos leva a pensar sobre as novas configurações sociais presentes nessa recente modernidade, na qual os antigos padrões e modelos explicativos não bastam mais para explicar o funcionamento das complexidades surgidas nas últimas décadas de nosso tempo.

Daí ser possível analisar as proposições do autor para caracterizar aquilo que denomina de modernidade líquida. Para ele, a liquidez - compreendida como expressão da sociedade dos nossos tempos - não tem uma forma definida, na medida em que é, metaforicamente, como fluídos que se moldam de acordo com os recipientes nos quais são colocados. Nessa perspectiva, os fluídos percorrem diferentes caminhos e ocupam os mais variados espaços.

Ainda de acordo com Bauman, a modernidade apresenta-se como um espaço de oportunidades que são perseguidas pelo indivíduo continuamente. Com isso, as tarefas que competem ao indivíduo são, de fato, do próprio indivíduo, que sofre a fragmentação do coletivo. Como resultado dessa correlação de forças, Bauman afirma que não vivemos mais em uma sociedade na qual simplesmente seguimos ou respeitamos normas impostas por governos ou Estados, mas sim escolhemos os caminhos de nossas próprias escolhas. Conviver em um corpo social impõe, dessa forma, a necessidade de interagir com o meio, observando as próprias convicções e respeitando regras mínimas impostas pela sociedade que nos cerca.

Longe de tentar estabelecer uma definição específica ou trazer explicações que correm o risco de desconsiderar aspectos relevantes da complexidade do conceito proposto por Bauman, buscamos aqui compreender quais são os principais desafios que se colocam por essa modernidade líquida, no que diz respeito especialmente ao campo da educação, objeto principal de nossa investigação. Dessa forma, quando 
nos referimos à modernidade em nossa análise, estamos fazendo-a na acepção defendida por Bauman.

Valendo-nos desse contexto de profundas transformações - de diferentes ordens, tais como políticas, econômicas, sociais, culturais, tecnológicas, entre outras -, deslumbramos um novo universo (Giddens, 2002) em que as fronteiras culturais parecem desabar diante de nossos olhos e levam-nos a compreender novas questões, como a diversidade de gênero, de raça, de religião e de várias outras que se apresentam na contemporaneidade.

Entretanto, ao mesmo tempo em que algumas fronteiras se desfazem, observamos o fortalecimento de outras, como a exclusão social, a indiferença em relação ao "outro", o isolamento social de jovens confinados em seus espaços de virtualidade e a formação de diferentes guetos nos espaços urbanos de nossas cidades.

Esses novos elementos da sociedade nos tempos da modernidade líquida levam-nos a refletir sobre as transformações pelas quais a sociedade vem passando, ao mesmo tempo em que nos aponta a necessidade de pensar sobre esses processos de exclusão, os quais denominamos de discriminação negativa (Castel,2011), em que a vontade e os interesses de certos grupos se sobrepõem aos demais.

Nesse mesmo contexto apresentam-se novas discussões - ou talvez nem tão novas assim, mas atualmente alvo de debates mais profundos -, como aquelas que questionam sobre o que é identidade e como sua construção na contemporaneidade se relaciona com o conceito de diferença. Afinal, o que é ser diferente? E é possível ser diferente no mundo atual?

Diante disso, podemos pensar na complexidade do tema e nas diferentes dimensões que envolvem esse conceito tão em voga na modernidade, o da identidade. Em nossa discussão, preocupamo-nos em pensar tal conceito pelo contexto que estamos inseridos, que é a escola brasileira. Nela percebemos uma multiplicidade de identidades que dão significação ao sujeito pelo jogo da diferença em relação aos outros (Hall, 2014), sendo fabricadas em diferentes esferas nas quais se manifestam elementos oriundos do local e do global (Woodward, 2014).

Nesse jogo que envolve a produção das identidades, o passado e o presente entram em conflito fazendo com que alguns elementos do passado sejam esquecidos, ou pelo menos deixados de lado, enquanto outros surgem e tornam-se representantes da identidade dos sujeitos, que passam a compartilhar ideias e valores culturais, que passam a representá-los em um processo de hibridização (Canclini, 2013) no qual as culturas manifestam elementos provenientes de diferentes tempos e lugares.

Dessa forma, encontramo-nos em uma sociedade que se transforma cada vez mais rapidamente e na qual os conceitos de identidade, fronteiras culturais e diferenças (Poutignat; Streiff-Fenart, 1998) tornam-se cada vez mais dinâmicos e passam a representar diferentes categorias. Com isso, a necessidade de melhor compreender a dinâmica dessas transformações coloca-se como ponto fundamental para todos, em especial para aqueles que se propõem a trabalhar com crianças e jovens no contexto da escola contemporânea. Os sujeitos mudam e por consequência as pautas que envolvem o cotidiano da escola também.

O hibridismo cultural (Canclini, 2013) e as diferenças identitárias (Hall, 2014) presentes na sociedade atual, e consequentemente na escola, colocam-se 
como pontos de partida para a discussão sobre o tema central de nosso estudo. Para compreender a necessidade de rever os modelos existentes para o ensino de história e propor alternativas que contribuam positivamente para a transformação dos sujeitos (nesse caso, os alunos), precisamos refletir acerca da complexidade que envolve a sociedade atual, com seus dilemas e inquietações, que naturalmente vão muito além do plano cultural.

Em nosso estudo, propomo-nos a estudar de maneira mais aprofundada algumas possibilidades que levam em consideração as complexidades anteriormente citadas. Diante dos novos sujeitos e de seus contextos - múltiplos -, pretendemos trazer à tona a discussão sobre a problematização dos lugares de memória, enquanto protagonistas das aulas de história na educação básica. Acreditamos que a exploração desse universo imagético presente nos diferentes lugares de memória (Nora,1993) que guardam fragmentos do passado - pode contribuir de forma significativa para a produção de saberes sobre o passado. Estes, por sua vez, devem produzir significado para o sujeito e lhe devem permitir a identificação e a associação (Silva, 2014) com esses lugares, historicamente construídos como parte de sua cultura e da formação de sua própria identidade e também do grupo do qual faz parte.

Os lugares de memória não devem ser compreendidos como algo alheio, distante e desprovido de significado. Ao contrário, o ensino de história pautado nessa prerrogativa deve contribuir para fazer com que os estudantes percebam as diferentes relações existentes entre os monumentos, museus, praças e diferentes lugares que guardam memórias e suas trajetórias de vida. Devem ser levados a questionar "os porquês" desses lugares, "quem foram" os vultos representados e "como foram parar" nesses ambientes que procuram guardar uma memória (Ricoeur, 2012), que por sua vez não deve cair no esquecimento.

Certamente, ao explorar esse universo de materialidade simbólica presente nos lugares de memória, que são também parte do patrimônio cultural (Choay, 2001), o professor de história fará com que seus alunos descubram um complexo processo que envolve a produção e a difusão de valores e ideias que estiveram presentes no processo de criação desses lugares. Com isso, esses sujeitos passam a reconhecer sua cultura também como resultado de interesses, de ideologias e do poder de determinados grupos, que muitas vezes impõem sua cultura.

A partir desse trabalho - exaustivo - de provocar nos alunos o exercício da crítica sobre a história, tendo como base os lugares à sua volta, acreditamos que o professor estará contribuindo para a formação de cidadãos críticos e reflexivos sobre a produção cultural existente no ambiente em que se insere.

Perceber que os nomes de ruas e avenidas não são atemporais e desprovidos de ideologias nos parece ser um passo importante para esse (re)inventar do ensino de história, no qual a história como disciplina do currículo escolar passa a ter uma dimensão que ultrapassa "as paredes" da sala de aula ou da linha de tempo feita com giz colorido que "cruza o quadro". Promover o ensino de história pautado em novas possibilidades metodológicas, mesmo em contextos em que as condições tecnológicas são escassas, é reinterpretar o passado, alavancando novos olhares sobre o que "já fomos". 


\section{MEMÓRIA(S), HISTÓRIA(S), ESQUECIMENTO(S) E ENSINO DE HISTÓRIA}

O vínculo que se estabelece entre as representações (Chartier, 2002) produzidas sobre o passado - compreendidas como diferentes narrativas, que podem ser escritas, visuais, sonoras etc. - e o contexto em que estas são produzidas é fator relevante na análise que pretendemos fazer. Isso se deve especialmente pelo fato dessas representações terem servido de instrumento para a justificação de toda uma produção e manipulação de saberes (Bourdieu, 2001) que, ao longo do processo histórico, foi alvo de diferentes interesses e ideologias. Estas, por sua vez, acabaram impondo certas visões sobre o passado que na maioria das vezes interferem diretamente na forma como ensinamos a(s) história(s) em sala de aula.

Parte dessa análise - que discute a relação entre a produção do saber histórico e seu ensino no contexto da modernidade líquida e suas diferentes dimensões culturais - baseia-se na investigação das novas configurações sociais que se expressam materialmente (entre outros elementos) por meio da urbanização presente em nossa sociedade - e da construção e nomeação de lugares - na qual a história é celebrada e (re)lembrada pelas gerações que se sucedem. Isso é perceptível na medida em que observamos a ereção de monumentos e a nomeação de inúmeros lugares e instituições que têm significados diversos.

Iniciamos nossa discussão valendo-nos da perspectiva apresentada pela historiadora Sandra Pesavento (2006), para quem a memória é um elemento indispensável para se compreender a construção das representações sociais e pelas quais se produzem diferentes narrativas sobre o passado.

Para Jacques Le Goff (2003), a memória é um elemento essencial do que se costuma chamar de identidade, seja ela individual ou coletiva, cuja busca é uma das atividades fundamentais das pessoas e da própria sociedade. Nesse sentido, a memória não é apenas conquista, mas também um instrumento de poder. Existe uma luta pela dominação da recordação e da tradição, estabelecendo aquilo que deve ser lembrado e aquilo que deve ser esquecido. Vale destacar que esse aspecto mostra-se bastante evidente na sociedade em que vivemos, na qual se verifica uma verdadeira imposição e manipulação de memórias (Ricoeur, 2012) por determinados grupos que, detendo em suas mãos o poder econômico e financeiro, acabam difundindo visões de mundo e modelos culturais pelo consumo de certos produtos e marcas que acabam mercantilizando as noções de felicidade e bem-estar.

Para pensarmos o processo que envolve a manipulação da memória e como é possível observá-la no campo da história, podemos conferir na história do Brasil vários exemplos pelos quais se procurou construir uma nova denominação para localidades que presenciaram conflitos marcantes, abalando a vida de seus moradores. Um desses exemplos pode ser encontrado no estudo realizado por Janice Theodoro (1997) em relação a Canudos, Bahia. A autora aponta para a importância do "apagamento" do local em que ocorreu o conflito, em 1897.

Em uma tentativa de apagar da memória coletiva o passado de Canudos - o mais expressivo movimento messiânico da história brasileira -, o território ocupado pelo arraial foi coberto pelas águas do açude de Cocorobó em 1968, em pleno regi- 
me militar. Frequentemente, no período das secas, podem ser vistas na área cruzes, ossadas e crânios, muros e peças de artilharia que trazem à tona a lembrança de um passado de horror que não se quer mais lembrar na atualidade. A tranquilidade das águas da represa simboliza a paz que voltou ao local.

Em nossa análise, consideramos que as representações sociais construídas sobre os lugares de memória (que normalmente são identificados como os lugares onde o fato histórico aconteceu) não se encontram apenas em textos historiográficos, mas também em diferentes formas narrativas. ${ }^{1}$ Tendo a concepção de que as representações sociais apresentavam-se de diversos modos, procuramos analisar como diferentes veículos de representação - textos historiográficos e literários, imprensa e cinema - acabaram difundindo determinadas concepções e pontos de vista sobre a história que será "contada". O aumento de fontes para pesquisa histórica, como as digitais e a difusão de um número incontável de informações disponíveis nas redes mundiais, coloca-nos diante da necessidade de alargar nossa compreensão sobre as fontes de pesquisa no que diz respeito a nosso passado - colocando acima de tudo a veracidade e confiabilidade das informações disponíveis - em um tempo de questionamentos profundos sobre as "verdades" e os "discursos" referentes ao passado.

Como nos ensina Antonio Celso Ferreira (2004), valendo-se dos estudos realizados por Stephan Bann, a caracterização e a análise das formas e conteúdos presentes nas representações sociais podem ser realizadas com base na investigação das mais variadas fontes. Entre elas, Ferreira destaca a análise realizada em textos historiográficos, os diversos tipos de discursos (jurídicos, médicos, filosóficos, teológicos), os textos literários e as pinturas, os museus, as narrativas cinematográficas, entre outras.

A análise das representações construídas sobre o cenário e os personagens centrais da história nos faz refletir a respeito do contexto em que cada autor se insere e, principalmente, sobre os propósitos que levam o autor a "contar" a história "dessa ou daquela" perspectiva. Da mesma maneira, torna-se evidente, em alguns casos, a preocupação por parte dos autores de legitimar sua versão sobre os fatos narrados, recorrendo a testemunhos orais ou até mesmo a referendar documentos cuja legitimidade muitas vezes poderia ser questionada.

Essa é, sem dúvida, uma das questões mais intrigantes da história e que, naturalmente, interfere no ato de ensinar história, uma vez que, ao ser ensinada na sala de aula, perpassa por toda essa produção, que carece de uma discussão epistemológica mais aprofundada. Em nossos dias, essa discussão nos parece ser urgente, uma vez que os modelos muitas vezes ainda empregados não respondem mais às, cada vez mais, complexas indagações dos nossos tempos e de toda a fluidez de ideias e inquietações trazidas pelos novos tempos.

1 Quando nos referimos aos diferentes tipos de narrativa, estamos tratando das diferentes formas com que elas se apresentam. Nesse caso, consideramos narrativas as representações sociais construídas e perceptíveis tanto em textos historiográficos e literários quanto na imprensa, no cinema e nos diferentes tipos de mídia de nosso tempo, imprimindo, dessa forma, certa visão sobre os fatos históricos veiculados. 
Essas questões nos fazem pensar naquilo que Michael Pollack (1989, p. 4) chamou de "trabalho de constituição e de formalização das memórias". Segundo o autor, para que nossa memória se beneficie da dos outros, não basta que ela nos traga apenas o testemunho, mas sim que encontre muitos pontos de convergência entre aquilo que queremos afirmar e as memórias de nossos testemunhos. Somente a partir do encontro dessas memórias - que são compartilhadas e que dão certa identidade ao grupo - é que podemos reconstruir as lembranças do passado sobre uma base comum.

Procuramos compreender como diferentes autores - que produzem discursos da história e, portanto, daquilo que chamamos de produção historiográfica - respaldam seus discursos tomando como base testemunhos e diferentes tipos de fontes, procurando dar veracidade às suas narrativas. Esse questionamento faz-se necessário para compreendermos como se dá a criação dos lugares de memória de nossas cidades, nos quais sua materialização é antecedida pela produção e difusão de certas ideias sobre os fatos e personagens envolvidos, sendo posteriormente "glorificados" por meio dos lugares de memória. Esses ambientes passam a ser vistos como lugares de perpetuação das memórias dos grupos que os produziram - porém nem sempre reconhecidos por todos.

As representações sociais construídas sobre o passado permitem-nos ainda pensar naquilo que Pollack denominou de "trabalho especializado de enquadramento" (idem, p. 11). De acordo com o autor, a memória é alvo de manipulações e defesa de interesses pessoais e coletivos, estando necessariamente relacionada com o contexto e com a época em que foi produzida.

Aliás, os discursos da atualidade estão amplamente ancorados nessa ideia, na qual a memória do passado serve de instrumento para tentar impor uma ideia de "progresso" e até mesmo de "evolução", imprimindo uma noção de vitória e conquista em relação aos "problemas do passado".

Quanto a essa questão, observamos que as representações construídas sobre o passado e que se revelam presentes nos livros didáticos de história - fonte de pesquisa e de estudo presente no cotidiano da sala de aula - inserem-se precisamente nesse contexto, no qual a memória é, muitas vezes, manipulada de forma que a imagem produzida sobre os fatos é enquadrada segundo os objetivos de cada autor e de acordo com sua época.

Com isso, torna-se significativo o questionamento acerca do processo que envolve a análise dos diferentes veículos de representação (documentos, filmes, imagens, livros, fontes digitais etc.) sobre o passado, observando em cada um deles a forma como retratam os lugares da história, seus protagonistas e seus diferentes enredos.

Considerando as afirmações de Michael Pollack, podemos ainda analisar as representações sociais ligadas àquilo que Jacy Alves de Seixas (2004, p. 53) descreveu como um conjunto de interesses coletivos, no "qual lembramos menos para conhecer do que para agir".

Segundo a autora, a memória está menos ligada ao processo de entendimento do passado, e sim diretamente identificada com os interesses que fazem as pessoas lembrarem-se de certo fato. Nesse sentido, a memória pode ser manipulada de acordo com os interesses de determinados grupos e épocas. $\mathrm{O}$ mesmo, podemos dizer, 
ocorre em sala de aula, na medida em que o professor de história é esse elemento mediador, que, ao tratar com as fontes, acaba interferindo também no processo de construção do conhecimento de seus alunos sobre o passado em questão.

De acordo com Seixas, não existe uma memória desinteressada. Ao contrário, a memória teria um destino prático, realizando a síntese do passado e do presente visando ao futuro, buscando os momentos passados para deles se servir. Dessa forma, "a memória carregaria, assim, um atributo fortemente ético, incidindo sobre as condutas dos indivíduos e dos grupos sociais" (idem, p. 53), procurando com isso induzir as condutas dos indivíduos na sociedade. Sem dúvida, essa teoria defendida pela autora ajuda-nos a entender a dinâmica que envolve a construção e a difusão das representações sociais sobre os diferentes acontecimentos do passado nas aulas de história e que, assim, acabam relacionando-se diretamente com o meio social.

No que diz respeito à questão que envolve a memória coletiva e a construção das representações sobre o passado nas aulas de história, devemos atentar para o estudo realizado pelo sociólogo francês Pierre Bourdieu (1998), que nos mostra como a produção de discursos está diretamente ligada ao contexto no qual estes se fazem presentes. Inseridos no campo das relações de poder, os discursos procuram estabelecer uma determinada ordem das coisas, seguindo interesses de ordem política, econômica, social e cultural.

Para Bourdieu (2001, p. 9), a produção dos discursos não ocorre de modo “inocente nem inconsciente", mas sim como resultado de interesses de certos grupos, detentores de um poder simbólico. Segundo o autor, esse poder age sobre as estruturas sociais, impondo certa visão dos fatos, transformando-os em "verdades absolutas" que permeiam e procuram ordenar o funcionamento da sociedade.

Os estudos realizados por Bourdieu ampliam nossa compreensão sobre o mundo caracterizado pela modernidade líquida e nos permitem descortinar os elementos "invisíveis" presentes na sociedade contemporânea. Segundo o autor, existem mecanismos estrategicamente elaborados para que determinados grupos tomem as decisões em nome da maioria, ainda que essa maioria não seja partícipe desse processo.

As diferentes formas de poder nos fazem refletir sobre as estratégias de execução e de como desempenha papel preponderante no campo cultural e, consequentemente, no processo que envolve o ensino da história, que também se torna um instrumento de poder, em especial no que se refere ao que "se quer ou não ensinar".

Assim, acreditamos que as representações sociais produzidas sobre o passado, e de forma especial sobre o processo que envolve o ensino da história no contexto escolar, vinculam-se a esse campo de poder (pedagógico), no qual algumas ideias podem ser ditas e outras precisam ser silenciadas. Isso pode ser exemplificado se tomarmos o período militar na história brasileira, no qual certas interpretações e visões não podiam ser "ditas" em sala de aula, uma vez que o regime político e a ideologia do período as consideravam ofensivas ao sistema em que se vivia.

Outra questão que nos parece não poder faltar no debate sobre a história e seu ensino é a produção da imagem dos heróis. Esse fato durante muito tempo habitou as páginas de livros didáticos e era, antes de tudo, reflexo de certas vertentes da historiografia. Estas, por sua vez, acreditavam que a história era explicada fun- 
damentalmente pelas ações de personagens heróicos, que assim determinavam os acontecimentos e os resultados dos percursos trilhados pela humanidade.

A presença de personagens como Luís XIV e Napoleão Bonaparte na história europeia, ou de D. Pedro I e Getúlio Vargas na história nacional, era colocada com tal "pompa" que nos fazia acreditar que se tratava de personagens cujos percursos e atitudes poderiam, "isoladamente", explicar toda uma conjuntura de acontecimentos. Nessa perspectiva, a construção da imagem heróica envolve diversos aspectos e demonstra, por parte de quem o produz ou o difunde (e nesse caso de forma especial temos o papel do professor de história), uma intencionalidade.

Aqui nos parece que a questão central do debate reside entre aquele professor que está preocupado em ensinar a história dos vencedores (e, portanto, reafirma a visão dos heróis) ou aquele que procura, pela dúvida posta sobre os supostos heróis do passado, questionar seus alunos quanto aos acontecimentos e ao contexto em que esses foram produzidos.

Nessa mesma linha interpretativa, poderíamos acrescentar a análise das representações sociais construídas sobre os cenários em que se inserem esses acontecimentos do passado. Sobre eles identificamos diferentes narrativas que se fazem presentes nas mais variadas obras que tratam da história e que, em diferentes momentos, procuraram caracterizar o espaço geográfico onde se desenvolvem a história a ser contada. Entretanto a falta de uma leitura crítica sobre esse aspecto muitas vezes impede a compreensão dos fatos e da própria relação que se estabelece entre a própria história e a dimensão geográfica/física do espaço sobre o qual se está falando.

Afinal, nos tempos da modernidade líquida (Bauman, 2003), o espaço real e concreto parece ter cada vez menos importância social, na medida em que passamos a viver cada vez mais em espaços de virtualidade e de relações midiatizadas. Nesse sentido, parece-nos urgente o resgate dos lugares físicos onde o passado foi produzido - e, portanto, precisa ser repensado.

Com base nessa análise, constatamos que determinados lugares - que aqui iremos chamar de lugares de memória em razão de estes constituírem-se em lugares físicos de lembrança sobre o passado - são representados por intermédio de diferentes veículos de representação, tais como documentos, textos historiográficos e literários, a imprensa e, ainda, o cinema, que atualmente muito tem produzido uma sensação de "verdade e autenticidade" a certos acontecimentos do passado, algo sobre o qual, sem dúvida, precisamos ficar mais atentos. Nesse sentido, a produção de algumas imagens sobre os lugares da história e presentes nessas diferentes fontes, e que por sua vez se traduzem em "discursos" sobre esse passado, é que acabam imprimindo certas visões - representações imagéticas - sobre o passado.

No contexto dessas reconfigurações sobre o que acreditamos ser uma possível reinterpretação dos caminhos em que se processam a história e seu ensino no âmbito da educação básica, devemos observar mais um aspecto importante. Trata-se da produção das diferentes representações construídas e difundidas no tocante a personagens históricos que durante muito tempo foram colocados no panteão dos heróis. Atualmente parece que estamos vivenciando uma mudança sensível nesse sentido, com a "crise dos heróis" e até mesmo com a "ausência de modelos", processo claramente perceptível na crise das ciências humanas do início do nosso século. 
Encontramos, muitas vezes em lados opostos, personagens que rivalizam e que são mostrados como os "únicos" responsáveis pela produção do enredo da história que está sendo contada, e assim acabam tendo seu perfil e suas ações interpretadas por diferentes ângulos. Essas interpretações, no entanto, acabaram contribuindo, na maioria das vezes, para a construção de uma imagem detratora da primeira, enquanto se construiu uma imagem heróica para o segundo, ou em ordem inversa, dependendo das circunstâncias envolvidas. É como se a história precisasse, a todo o momento, encontrar culpados e inocentes para justificar as ações humanas no tempo pretérito.

Nesse caso, os personagens mostrados são antagônicos, em que a narração das virtudes de um serve de desqualificação para o outro, já que se encontram em "lados opostos" no conflito. Tanto o "mocinho" quanto o "bandido" da história produzida por esse discurso sobre o passado têm suas representações construídas por meio de um contraponto que é estabelecido entre ambos os personagens.

De acordo com nossa análise, parte das narrativas construídas sobre o passado - e que se manifesta materialmente nos textos de história e na criação e nomeação dos lugares (físicos) da memória (como praças, monumentos e diferentes espaços sociais) - procurou incutir no imaginário do leitor a noção de "verdade", fazendo com que o discurso do autor pareça e assuma a condição de descrição fiel de seus personagens e fatos. Afinal, o que se quer por meio disso é produzir uma sensação de "fidelidade" em relação àquilo que está sendo narrado pelo texto de história.

Com isso, "os traços de heroísmo, de virtudes cívicas, oferecidos aos olhos do povo, eletrificam suas almas e fazem surgir as paixões da glória, da devoção à felicidade de seu país" (Carvalho, 1990, p. 11). Essas ações manifestam-se muitas vezes, e de forma especial, em alguns materiais didáticos, carregados de adjetivações essencialmente ideológicas que procuram solidificar certas imagens sobre esse passado idealizado.

Essa visão de ensino de história, que prioriza os personagens centrais e os coloca no panteão dos heróis, é, em nosso entendimento, uma visão distorcida da realidade e muito contribui para a difusão de um conhecimento parcial e acrítico da realidade - que por sua vez contribui para a manipulação e o controle do poder (Bourdieu, 2001) em uma sociedade que se modifica a todo o momento, mas que precisa manter o poder nas mãos dos mesmos grupos historicamente constituídos.

Ressaltamos, com isso, que não devemos desconsiderar os demais personagens envolvidos na construção do processo histórico. Estes, sem dúvida alguma, permitem-nos compreender o contexto de inserção dos personagens centrais da história, ao mesmo tempo em que tornam compreensível a projeção daqueles como responsáveis pela liderança, em muitos casos de grupos rivais. Daí ser possível interpretar criticamente o enredo presente nesse passado que passa a ser analisado e, por consequência, ensinado em sala de aula. Romper com a visão de uma história "vista de cima" parece algo já dito, mas que precisa sempre ser relembrado no ambiente de aula.

A eleição dos protagonistas da história como representantes dos dois lados do conflito remete-nos à análise feita por José Murilo de Carvalho, para quem o processo de "heroificação" inclui necessariamente a "transmutação da figura real, a fim de torná-la arquétipo de valores ou aspirações coletivas" (Carvalho, 1990, p. 14). 
Carvalho nos chama atenção para o fato de que, "por ser parte real, parte construído, por ser fruto de um processo de elaboração coletiva, o herói nos diz menos sobre si mesmo do que sobre a sociedade que o produz" (idem, ibidem).

\section{AS (NOVAS) PREOCUPAÇÕES DA HISTÓRIA NA LIQUIDEZ DO(S) TEMPO(S)}

Com base nas inquietações manifestadas até aqui é que iremos refletir sobre aquilo que Halbwachs (2004) chama de memória coletiva, e que em nosso estudo parece representar um ponto fundamental na medida em que a memória tem sido alvo, especialmente nas duas últimas décadas, de manipulações. Essas manipulações operam por meio de diferentes meios de difusão cultural, como as redes sociais e os diversos tipos de mídia, que espetacularizam o passado fazendo uso de imagens e de movimentos que buscam sensibilizar e produzir sensações sobre o vivido e sobre os lugares que a ele são remetidos.

De maneira especial, Halbwachs mostra-nos como os lugares desempenham um papel fundamental na construção da memória coletiva. Para o autor, os lugares que percorremos nos fazem lembrar de fatos ocorridos no passado e, assim, contribuem para a construção da memória coletiva.

A construção de monumentos, a denominação de lugares e a preocupação com a valorização de personagens do passado estão diretamente associadas a uma memória coletiva. Quando uma comunidade elege seus lugares de memória e também seus símbolos e heróis - que passam a representá-la -, pode-se perceber os condicionantes que estiveram envolvidos nesse processo de construção das representações.

Tendo essas questões, que nos levam a refletir sobre o papel da história no contexto atual, procuramos discutir como os diferentes temas ensinados na história (como disciplina no currículo escolar) passaram - e continuam passando - por um processo de (res)significação. Se observarmos a produção da memória sobre diferentes temas da história sul-riograndense - como é o caso da Revolução Farroupilha ou até mesmo das origens do gaúcho -, iremos perceber como se operam essas produções mentais e simbólicas da história.

A manipulação do passado do Rio Grande do Sul - assim como o de qualquer outro estado brasileiro -, nesse contexto, pode servir de exemplo para compreendermos como se operam esses processos de heroicização e de criação de lugares de memória, que pretendem glorificar personagens e lugares - na medida em que buscam perpetuar uma memória sobre esse passado - que atendam aos interesses de determinados grupos sociais, que se representam por essa imagem autoconstruída sobre o passado. Imagens de heróis e passagens de conflitos pretensamente gloriosos marcam, sem dúvida, esse passado de forma evidente.

Poderíamos ainda citar diversos exemplos dessas "distorções" presentes na história nacional e mundial, mas infelizmente nos perderíamos em incontáveis exemplos ricos em detalhes e apaixonantes pela natureza que nos trazem. Coerentes com uma nova visão interpretativa da história, os lugares de memória têm uma 
função importante na difusão e na consagração das imagens produzidas sobre o passado. Para Michel Pollack (1989), os lugares de memória somente se constituem em espaço de preservação de uma memória se assim a comunidade os reconbece - o que nos leva a pensar sobre a crise de memória que estamos vivendo atualmente, na medida em que passamos a não mais reconhecer esses espaços materiais encontrados a nossa volta.

Acrescente-se a isso a constatação de que os lugares de memória construídos sobre os diferentes episódios do passado, como a Revolução Farroupilha anteriormente citada, são elaborados no momento em que lideranças políticas e diferentes segmentos da sociedade sentem a necessidade de materializar uma versão sobre o fato e de utilizá-la estrategicamente. Nessa perspectiva, os lugares de memória não somente terão seu significado reconhecido pela sociedade, como impedirão que ela o esqueça, forçando para que se posicionem tanto em relação ao passado quanto em relação ao futuro almejado.

O historiador José Murilo de Carvalho (1990) refere-se à associação existente entre a construção dos imaginários sociais e a criação de diferentes símbolos para reforçar uma dada visão sobre o passado. Para ele, a manipulação dos símbolos, das alegorias e até mesmo dos mitos criados sobre os personagens históricos nos ajuda a compreender a dinâmica que envolve a construção dos imaginários sociais.

Ainda com relação à dinâmica que envolve a análise das representações sociais e à construção dos lugares de memória, resgatamos aquilo que Sandra Pesavento (2002) chama de "ressemantização do tempo e do espaço". Para ela, é preciso considerar as transformações de caráter econômico, político, social e cultural, para que se torne possível a realização de uma leitura das representações sociais construídas em dado contexto. Nesse sentido, a época e o espaço no qual ocorreram essas construções devem ser levados em consideração para que as representações tornem-se parte integrante da coletividade da qual fazem parte.

De acordo com Pesavento, é preciso considerar o fato de que as representações são produzidas social e historicamente, não sendo anacrônicas, deslocadas ou necessariamente falsas, uma vez que traduzem formas de sentir, pensar e ver a realidade. Entendemos, portanto, que a construção das representações sociais sobre os fatos do passado - e que foram materializadas naquilo que chamamos de lugares de memória - estão diretamente vinculadas ao contexto da época de seu surgimento. A criação dos lugares de memória atuam nesse sentido, de (re)lembrar e manter viva na memória das pessoas aquilo que se quer mostrar e aquilo que se quer "apagar" da memória social.

Para Maurice Halbwachs (2004, p. 30), nossas lembranças "permanecem coletivas, e elas nos são lembranças pelos outros, mesmo que se trate de acontecimentos nos quais só nós estivemos envolvidos, e com objetos que só nós vimos". Em outras palavras, Halbwachs nos mostra como a memória não é resultado de um trabalho individual, mas sim resultado do trabalho coletivo.

Fundamental para se pensar o ensino da história por meio da interpretação dos significados que os lugares de memória exercem na compreensão dos conteúdos historiográficos é mostrar na sala de aula que esses espaços são, antes de tudo, dotados de um significado simbólico. Ou seja, esses lugares nos remetem a pensar a 
respeito dos fatos que ali ocorreram e de pessoas que ali estiveram. É nesse sentido que destacamos a criação dos diferentes lugares de memória (monumentos, praças, instituições etc.) e os vinculamos ao processo de (res)significação da história, uma vez que os tomamos como evidência das visões e dos sentimentos coletivos que se faziam presentes na época de sua criação.

Consideramos a afirmação apresentada por Meneses (2004) bastante esclarecedora na análise a que nos propomos realizar sobre os lugares de memória de uma cidade. Para o autor, “a cidade é mais que espaço físico; é mais que materialidade. Ela é o lócus continuum de cultura, onde natureza, construção material, símbolos, significados e representações se constroem em diversidade e em harmonia" (idem, p. 87).

Embasando nossa análise sobre monumentos históricos que nos levam a refletir e a (re)lembrar os fatos do passado, recorremos aos estudos realizados por Françoise Choay (2001). De acordo com essa autora, o sentido original do termo "monumento" é do latim monumentum. Este, por sua vez, deriva de monere, que significa "advertir" ou "lembrar". Para a autora, o monumento tem como propósito essencial não apenas o de apresentar ou dar uma informação neutra. Ao contrário, o monumento tem, segundo Choay, a intenção de tocar uma memória viva pela emoção (idem, p. 18).

Considerando que os monumentos construídos pela comunidade não estão dispostos de forma inocente ou desprovidos de significação, estando diretamente relacionados com a história da comunidade que os erigiu, assim como com os interesses de seus "construtores", podemos acrescentar que: "Para aqueles que edificam, assim como para os destinatários das lembranças que veiculam, o monumento é uma defesa contra o traumatismo da existência, um dispositivo de segurança. $\mathrm{O}$ monumento assegura, acalma, tranquiliza, conjurando o ser do tempo"(idem, ibidem).

Dessa forma, evidencia-se a eficácia simbólica exercida pelos monumentos. Localizados estrategicamente no espaço social das cidades, os monumentos representam formas de pensar, sentir e expressar os valores coletivos.

Tomados como simbolos espaciais (Oliveira, 2003), os diferentes monumentos históricos, assim como outros tantos símbolos que passam a representar parte da história de um lugar, devem ser entendidos como resultado de diferentes interesses - até mesmo antagônicos às vezes - e anseios presentes nessa comunidade. É justamente esse antagonismo que torna possível pensarmos os dois monumentos pela perspectiva da construção de alteridades históricas. Isto é, o valor simbólico atribuído por uma comunidade em relação aos seus objetos tem muitas vezes significados contraditórios, dependendo dos grupos que os produzem.

O antropólogo Luiz Antônio de Oliveira (2003) mostrou como o relato histórico é elaborado, constituindo uma trama histórico-religiosa na qual o passado é teatralizado. Destaca ainda que os locais em que ocorrem conflitos de caráter religioso tornam-se bem-aventurados, em contraste com as ações antagônicas de seus personagens, fabricando aquilo que ele chama de alteridades históricas. Ainda segundo o antropólogo, uma comunidade procura sempre "atualizar" sua história, para, a partir dos supostos erros do passado, construir uma nova identidade para o local.

Contrapondo-se a esse processo de valorização, constata-se que cenas e personagens do passado são, propositalmente, muitas vezes "esquecidas" tanto pelas 
fontes quanto pelas próprias escolhas feitas por quem as manipula, evidenciando o que Oliveira denomina de celebração da história. Para o autor, esse processo no qual episódios do passado - percebidos como bens simbólicos - são submetidos ao inventário dos interesses presentes elege fatos e personagens que devem (ou não) ser lembrados.

O diálogo que se estabelece entre o passado e o presente que se está vivendo produz um "discurso" sobre o passado. Um discurso - é preciso lembrar - circunstanciado pelos diferentes contextos e pelas múltiplas interlocuções, dependente diretamente da ótica de quem está "lendo" os vestígios do passado.

Nessa perspectiva de discutir criticamente a produção dos diferentes discursos sobre o passado (sejam eles documentos, monumentos ou os mais diversos lugares de memória), destacamos aquilo que Roger Chartier (2002) afirma quando trata das inúmeras possibilidades de leitura de um símbolo, afirmando que este nunca é "lido" de uma única maneira.

Consequentemente, pode-se dizer que os símbolos construídos sobre o passado têm a finalidade de "educar" os olhares de uma comunidade, interferindo de forma determinante no "tipo" de história que se está ensinando.

Acreditamos ser válido agregar a essa discussão em torno dos símbolos e sua difusão por meio do ensino da história a questão que envolve as rupturas e a construção de novas "tradições" pelas sociedades em momentos de transformações rápidas.

Para tanto, resgatamos a afirmação de Eric Hobsbawm e Terence Ranger (1997), que contribuíram para a reflexão a que aqui nos propomos, na medida em que critica a forma como muitas sociedades manipulam indiscriminadamente os discursos sobre seu passado.

A partir daí observamos uma clara relação entre os discursos produzidos sobre o passado (e que se manifestam em textos didáticos e nas mais diferentes fontes de estudo empregadas pelo professor de história em sala de aula) e a invenção - e difusão - de determinadas verdades sobre esse passado.

O imaginário, vale lembrar, tem como um de seus pontos de referência - e de lembrança - os lugares de memória, na expressão de Pierre Nora (1993, p. 25), para quem "a memória pendura-se em lugares, assim como a história em acontecimentos". Acreditamos que símbolos, como o hino, a bandeira e a própria criação de monumentos alusivos a um novo regime político, bem como a renomeação de lugares de memória das mais diferentes cidades, que passam a contar com nomes que referendam personalidades e feitos, desempenham um papel preponderante na consolidação da nova ideologia que diferentes grupos de poder procuram difundir.

Cabe aqui lembrar aquilo que o historiador José Newton Coelho Meneses (2004, p. 31) afirma quando se refere ao papel desempenhado pelos monumentos históricos. Para Meneses os monumentos "busca[m] tornar viva a memória de algo importante e identitário socialmente. Nesse caso, ele[s] têm, necessariamente, como mediadores, a memória construída e a história”.

Os lugares de memória - espalhados por nossas cidades - constituem-se, dessa maneira, em materializações dos sentimentos e dos interesses predominantes em cada época. Sentimentos e interesses que acabaram por determinar a condenação ou a celebração, a memória ou o esquecimento dos episódios e de seus personagens. 


\section{CONSIDERAÇÕES FINAIS}

Articular novas questões - urgentes - de cunho metodológico com concepções de cidadania, identidade cultural e educação patrimonial, procurando nos lugares de memória possibilidades de exploração dos sentidos produzidos sobre o passado não é tarefa fácil. Assim como identificar, por meio do estudo da história inserida em um contexto de transformações cada vez mais rápidas - que caracterizam a liquidez de nossos tempos -, as possibilidades de interpretação do significado que as materialidades simbólicas produzem, como os monumentos e museus nos novos sujeitos aprendentes.

Aprender a olhar e perceber nas materialidades expostas nos espaços físicos coloca-nos diante da necessidade de interpretar a complexidade das ações humanas, seu passado e suas produções simbólicas, que operam no sentido da manipulação das identidades, das representações e, por consequência, das ações humanas. Despertar em crianças e jovens, pelo ensino da história, a consciência sobre a materialidade que nos cerca é colocar em pauta o exercício da crítica sobre o passado e contribuir para uma cultura da "não virtualidade", transformando os espaços concretos e visíveis das cidades em lugares que guardam memórias e que nos ajudam a compreender o passado.

A criação de determinadas visões sobre o patrimônio cultural, ancoradas em seus lugares de memória, reproduzem-se ou transformam-se nos espaços da escola, que podem provocar em seus aprendentes novas interpretações sobre o passado e sobre o contexto em que se fizeram tais produções simbólicas. Perceber os lugares de memórias e sua materialidade como potencializadores de uma história crítica, cidadã e portadora de identidades, que falam sobre o passado, é sem dúvida uma ação desafiadora, ao mesmo tempo em que se coloca como uma questão urgente dos nossos tempos.

Em meio à liquidez, ao desenraizamento das identidades locais e à emergência de novos modelos globalizados, as novas tecnologias - como redes sociais e a difusão das imagens instantâneas - colocaram o passado sob julgamento na sala de aula. Em especial nas aulas de história, o passado das civilizações pode correr o risco de perder "seu sentido", na medida em que a instantaneidade das ações do presente pode levar ao descrédito sobre o passado distante, contribuindo para a perpetuação do imediatismo das coisas. Ao mesmo tempo, leva-nos a acreditar na possibilidade da vida como um processo de felicidade instantânea e plena, na qual não existe espaço para problemas concretos e desilusões.

Talvez nossa discussão ultrapasse os limites daquilo que "um bom professor de história" atento às "mudanças repentinas do tempo" tenha como propósitos. Pensar a história - como disciplina do currículo escolar - leva-nos inevitavelmente a refletir sobre os papéis sociais que o ensino de história pode desempenhar nesse "circuito de mudanças", que é o tempo presente. Trazer à tona a solidez dos espaços físicos - mas também sociais e simbólicos - que petrificaram o passado em pedra, madeira ou aço pode ser, em nossa análise, uma possibilidade de investigação da história, preocupada com a construção de narrativas possíveis, inscritas na quase total liquidez de nossos tempos. 
A espetacularização dos acontecimentos e a instantaneidade com que eles chegam fazem refletir sobre os ciberespaços do mundo à nossa volta e nos leva, cada vez mais, a insistir na necessidade de o ensino de história voltar-se cada vez mais para a leitura de mundo e de seus espaços, buscando assim a articulação entre os fenômenos globais e locais - entre onde queremos chegar e o lugar em que estamos agora.

\section{REFERÊNCIAS}

Bauman, Z. O mal estar na pós-modernidade. Rio de Janeiro: Zahar, 1998. Globalização: as consequências humanas. Rio de Janeiro: Zahar, 1999. . Modernidade líquida. Rio de Janeiro: Zahar, 2003.

Bourdieu, P. A economia das trocas linguísticas. São Paulo: EDUSP, 1998. O poder simbólico. 4. ed. Rio de Janeiro: Bertrand Brasil, 2001.

Burke, P. Testemunba ocular. História e imagem. Bauru: EDUSC, 2004.

Canclini, N. G. Culturas híbridas. 4. ed. São Paulo: EDUSP, 2013.

Carvalho, J. M. A formação das almas: o imaginário da República no Brasil. São Paulo: Companhia das Letras, 1990.

Castel, R. A discriminação negativa. Cidadãos ou autóctones? 2. ed. Petrópolis: Vozes, 2011.

Chartier, R. À beira da falésia. A história entre certezas e inquietude. Porto Alegre: Editora da UFRGS, 2002.

Снону, F. A alegoria do patrimônio. São Paulo: Editora UNESP, 2001.

FERreira, A. C. Heróis e vanguardas, romance e história: os intelectuais modernistas de São Paulo e a construção de uma identidade regional. In: Pesavento, S. J. (Org.). Escrita, linguagem, objetos: leituras de história cultural. Bauru: EDUSC, 2004.

Giddens, A. Modernidade e identidade. Rio de Janeiro: Zahar, 2002.

Hall, S. A identidade cultural na pós-modernidade. 11. ed. Rio de Janeiro: DP\&A Editora, 2006.

Quem precisa de identidade? In: Silva, T. T. (Org.). Identidade e diferença. A perspectiva dos estudos culturais. 14. ed. Petrópolis: Vozes, 2014.

Halbwachs, M. A memória coletiva. São Paulo: Centauro, 2004.

Hobsbawm, E.; Ranger, T. A invenção das tradições. 2. ed. Rio de Janeiro: Paz e Terra, 1997.

Le Goff, J. História e memória. 5. ed. Campinas: Editora da UNICAMP, 2003.

Meneses, J. N. C. História e turismo cultural. Belo Horizonte: Autêntica, 2004.

Nora, P. Entre memória e história. A problemática dos lugares. Projeto História, São Paulo: PUC, n. 10, p. 7-28, dez. 1993.

Oliveira, L. A. O teatro da memória e da história: alguns problemas de alteridade nas representações do passado presentes no culto aos mártires de Canhaú-RN. Revista de Humanidades, Fortaleza: UNIFOR, v. 4, n. 8, p. 80-110, abr./set. 2003. 
Oliveira, L. L. A construção do herói no imaginário brasileiro de ontem e de hoje. In: Pesavento, S. J. (Org.). História cultural: experiências de pesquisa. Porto Alegre: Editora da UFRGS, 2003. p. 65-81.

Pesavento, S.J. O imaginário da cidade. Visões literárias do urbano. Paris, Rio de Janeiro, Porto Alegre. Porto Alegre: Editora da UFRGS, 2002.

Palavras para crer. Imaginários de sentido que falam do passado. Nuevo Mundo Mundos Nuevos, [S.1.: s.n.], n. 6, p. 4, 2006. Disponível em: <http://nuevomundo.revues. org/document1499.html>. Acesso em: 10 set. 2014.

Pollack, M. Memória, esquecimento, silêncio. Estudos Históricos, Rio de Janeiro: FGV, v. 2, n. 3, p. 3-15, 1989.

Poutignat, P.; Streiff-Fenart, J. Teorias da etnicidade. Seguido de grupos étnicos e suas gronteiras de Frederik Barth. São Paulo: Editora UNESP, 1998.

Ricoevr, P. A memória, a história, o esquecimento. Campinas: Editora UNICAMP, 2012.

Seixas, J. A. Percursos de memórias em terras de história: problemas atuais. In: Bresciani, S.; Naxara, M. (Orgs.). Memória e (res)sentimento: indagações sobre uma questão sensível. Campinas: Editora UNICAMP, 2004. p. 37-58.

Sinva, T. T. (Org.). Identidade e diferença: a perspectiva dos estudos culturais. 14. ed. Petrópolis: Vozes, 2014.

Theodoro, J. Canudos 100 anos depois: da vida comunitária ao surgimento dos movimentos fundamentalistas. In: Abdala Júnior, B.; Alexandre, I. (Orgs.). Canudos: palavra de Deus sonho da terra. São Paulo: SENAC; Boitempo Editorial, 1997.p. 89-99. WoodWARD, K. Identidade e diferença: uma introdução teórica e conceitual. In: SiLVA, T.T. (Org.). Identidade e diferença: a perspectiva dos estudos culturais. 14. ed. Petrópolis: Vozes, 2014. p. 7-40.

\section{SOBRE O AUTOR}

Daniel Luciano Gevehr é doutor em história pela Universidade do Vale do Rio dos Sinos (UNISINOS). Professor das Faculdades Integradas de Taquara (FACCAT).

E-mail: danielgevehr@hotmail.com

Recebido em outubro de 2014

Aprovado em março de 2015 